\title{
Os Fundamentos da Constituição Subjetiva Segundo Laplanche
}

\author{
The Foundations of Subjective Constitution \\ According to Laplanche
}

RESUMO Este artigo apresenta a concepção de subjetividade na teoria de Jean Laplanche a partir de sua problematização da teoria das pulsões na metapsicologia que levou à proposta da teoria da sedução generalizada. O objetivo é mostrar como nessa concepção a alteridade se apresenta de forma traumática na constituição originária da subjetividade, endossando certas posições na literatura psicanalítica que defendem a violência simbólica como aspecto fundamental do sujeito do inconsciente.

Palavras-chave PSICANÁlISE; JEAN LAPLANCHE; ALTERIDADE. SEDução GENERALIZADA.

ABSTRACT s article presents the concept of subjectivity in the theory of Jean Laplanche from his questioning of metapsychology's drive theory which led to the proposal of the theory of generalized seduction. The objective is to show how in this conception otherness is presented in a traumatic way in the primary constitution of subjectivity, endorsing certain positions in the psychoanalytic literature that advocate symbolic violence as a fundamental aspect of the subject of psychoanalysis.

KEYWORDS Psychoanalysis; Jean Laplanche; Otherness; Generalized seduction.

\section{INTRODUÇÃO}

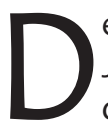

entre os psicanalistas de língua francesa, certamente Jean Laplanche é o nome mais conhecido depois de Jacques Lacan. Tamanho sucesso se deve provavelmente à grande penetração de sua obra mais conhecida, o Vocabulário da Psicanálise, escrita em parceria com Jean-Bertrand Pontalis, no meio acadêmico da psicologia e da psicanálise no Brasil. Tal vocabulário é bibliografia básica de qualquer curso de psicanálise e foi responsável pela consolidação de um sotaque francês no jargão psicanalítico nacional. A importância de Laplanche, contudo, não se reduz a esse feito. Além de contribuições teóricas e metodológicas fundamentais, esse autor é até hoje figura importante no movimento psicanalítico internacional, sendo responsável por nada menos do que a coordenação da atual edição das obras completas de Freud na França.

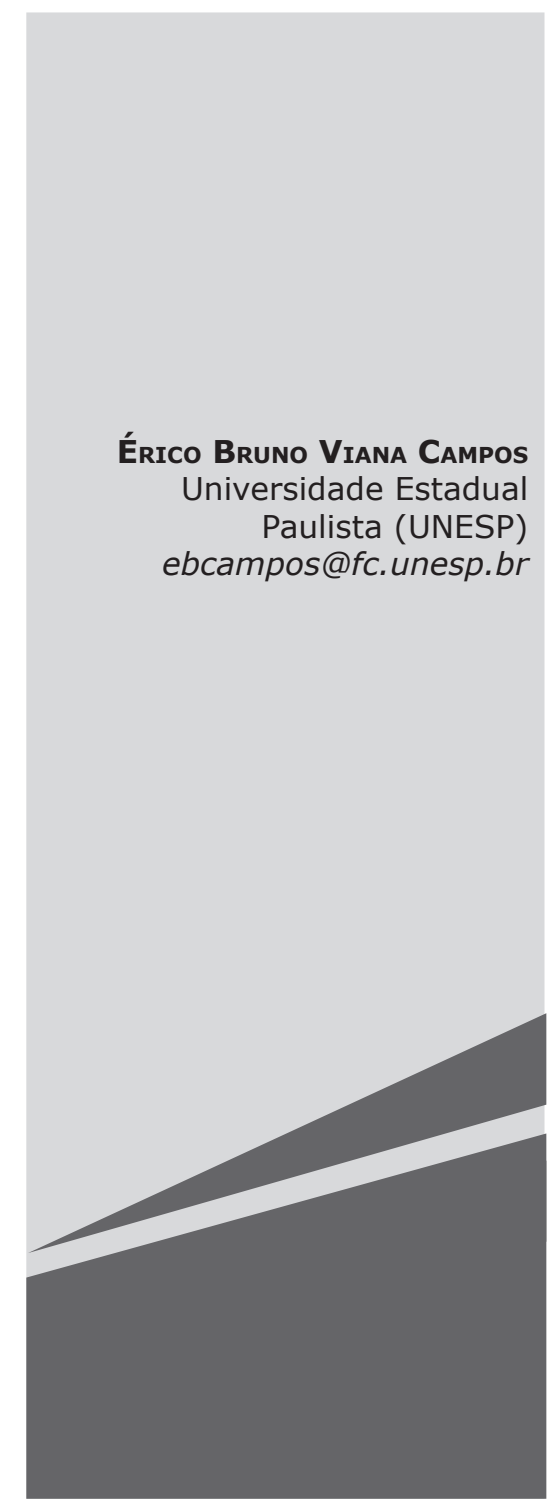


O propósito deste artigo é apresentar minimamente o percurso autoral de Laplanche em sua inserção no movimento psicanalítico francês e mundial, destacando a sua relevância para a Psicanálise Contemporânea. Para tanto, iremos apresentar as principais contribuições teóricas de Laplanche para a Psicanálise, todas partindo de problemáticas intrínsecas à obra de Freud e ao contexto psicanalítico em que se desenvolveu. São elas: (1) as aplicações do método psicanalítico e a renovação da escuta psicanalítica; (2) a teoria das pulsões e o desvio biologizante; (3) a teoria da sedução generalizada e as origens do psiquismo. Em todas essas frentes, a obra de Jean Laplanche aponta para o papel da alteridade na constituição da subjetividade e da teoria psicanalítica. Como veremos, essa problemática, por sua vez, implica discussão sobre a ética da psicanálise que aponta para uma matriz intersubjetiva traumática na constituição do sujeito.

\section{TRAJETÓRIA DE LAPLANCHE}

Jean Laplanche, nascido em 21 de junho de 1924, é um psicanalista pertencente à terceira geração de analistas franceses. Sua formação inicial foi na Escola Normal Superior, tendo passado um período na Universidade de Harvard, obtendo agregação em Filosofia, em 1950. Nesse mesmo ano, começou a fazer terapia psicanalítica com Jacques Lacan. Empreendeu a seguir uma formação médica e, posteriormente, deu início à formação em psicanálise. Quando iniciou sua formação propriamente analítica, tomou partido da recém-criada Sociedade Francesa de Psicanálise (SFP), originada em 1953 a partir de uma cisão liderada por Daniel Lagache, Jacques Lacan e Françoise Dolto na Sociedade Psicanalítica de Paris (SPP) em torno da questão da análise leiga. Seguiu assim seu analista e posterior mentor, tornando-se um dos principais discípulos iniciais de Lacan.

Contudo, a sua adesão ao movimento lacaniano logo levou a algumas diferenças teóricas, em especial por meio de críticas à radicalidade dos pressupostos linguísticos e estruturalistas que marcaram a segunda fase do pensamento de Lacan. Essas diferenças acabaram por ser explicitadas em evento acadêmico que marcou época na história da psicanálise francesa: o III Colóquio de Bonneval, organizado pelo psiquiatra Henri Ey, em 1960 (EY, 1969), que contou com a participação de muitos autores acadêmicos de destaque discutindo a questão do inconsciente:

Foi no Colóquio de Bonneval, em 1960, que a tese lacaniana da primazia da linguagem sobre $o$ inconsciente viu-se discutida por dois dos mais brilhantes discípulos do mestre: Serge Leclaire e Jean Laplanche. Em sua exposição intitulada "O inconsciente: um estudo psicanalítico", cada um desses dois autores formulou uma posição diferente. Enquanto Leclaire demonstrou, através de um caso clínico (o "Homem do Licorne"), a validade da proposição da primazia do significante, Laplanche, ao contrário, inverteu-a, sustentando a idéia de que "o inconsciente é a condição da linguagem" (ROUDINESCO e PLON, 1998, p. 378).

Assim, pode se afirmar que Laplanche foi discípulo de Lacan até meados de 1960, quando iniciou um percurso próprio de teorização e de ensino. Nisso foi muito influenciado por Daniel Lagache, aquele que foi, com Jacques Lacan, um dos principais estimuladores do desenvolvimento da psicanálise no meio universitário francês. Foi por meio do convite de Lagache que Laplanche passou a ensinar na Sorbonne, o que levou também à proposição do projeto do famoso Vocabulário da Psicanálise, que tinha como meta ser um livro de referência de caráter didático, mais adequado aos padrões acadêmicos de ensino. Esse projeto, dirigido por Lagache e desenvolvido por Laplanche em parceria com outro psicanalista da SFP, Jean-Bertrand Pontalis, foi publicado em 1967 e logo se tornou obra 
de referência mundial, tendo sido traduzido para mais de 15 idiomas.

Laplanche não seguiu Lacan no novo cisma do movimento psicanalítico francês que ocorreu em 1964, tendo permanecido como membro da SFP e, por conseguinte, fazendo parte da Associação Psicanalítica da França organização fundada naquele mesmo ano e que passou a reunir as duas sociedades francesas reconhecidas pela Associação Psicanalítica Internacional (IPA). Partindo da experiência universitária na Sorbonne, Laplanche prosseguiu para a Universidade de Paris VII, onde participou da implantação da Unidade de Ensino e Pesquisa (Unité d'Enseignement et Recherche - UER) de Ciências Humanas Clínicas, que foi o primeiro departamento de pesquisa e formação psicanalítica no meio universitário francês.

Esse movimento de entrada da psicanálise na Universidade de Paris VII foi complementado pelo trabalho de outro pesquisador e teórico, Pierre Fédida, que implementou um laboratório de estudos em psicopatologia com forte base psicanalítica, o que contribuiu para que aquela instituição tenha sido a grande pioneira no desenvolvimento de pesquisa psicanalítica universitária e seja referência até hoje nesse campo. Foi no contexto desse departamento que Laplanche estabeleceu seu ensino e pesquisa em psicanálise, desenvolvidos a partir de 1969 na forma de seminários semestrais que versavam sobre problemáticas específicas da obra de Freud. Esses seminários foram posteriormente, já na década de 1980, publicados na forma de livros, gerando a coleção homônima Problemáticas: I - A Angústia (LAPLANCHE, 1998); II - Castração e Simbolizações (LAPLANCHE, 1988d); III - A Sublimação (LAPLANCHE, 1989); IV - O Inconsciente e o Id (LAPLANCHE, 1992b); V - A Tina: a transcendência da transferência (LAPLANCHE, 1993).

O trabalho de Laplanche constituiu uma tradição de estudos rigorosos do pensamento freudiano baseados naquilo que, apesar das reservas do próprio autor com relação aos termos, podemos chamar de uma hermenêutica da obra freudiana. [Não sei se é uma boa palavra... Laplanche critica muito a hermenêutica e diz não a estar fazendo. Evidentemente, não é por isso que ela não deva ser usada, mas, se se vai fazê-lo, é preciso lembrar desse porém e justificar o uso]. Sua proposta é fazer uma leitura interpretativa propriamente psicanalítica, o que, aliado ao trabalho de formação de pesquisadores, conferiu a esse autor uma grande autoridade e reputação no campo teórico e conceitual da psicanálise. Coube a ele também um papel importante na divulgação do saber e das pesquisas psicanalíticas, o que fez que dirigisse alguns projetos editoriais importantes em parceria com a Presses Universitaires de France (PUF), em especial a Biblioteca de Psicanálise, de 1973, a coleção Novas Vozes em Psicanálise, de 1979, e a Revista Psicanálise na Universidade, de 1975 a 1994.

Tamanha reputação acadêmica na leitura e interpretação de textos freudianos levou Laplanche a ser considerado uma verdadeira sumidade em terminologia psicanalítica, o que acabou resultando no convite, no final da década de 1980, para ser o coordenador editorial da tradução francesa das Obras Completas de Freud (LAPLANCHE, COTET E BOURGUIGNON, 1992 ; ROUDINESCO e PLON, 1998). Tratava-se de uma tarefa árdua, uma vez que embora tenha se constituído uma ampla tradição francesa de psicanálise, até então não havia uma tradução uniforme e completa das obras de Freud na França, estando os textos publicados em diferentes traduções por diferentes editoras. Além da dificuldade propriamente editorial, havia agora, depois de inúmeras cisões no movimento psicanalítico francês, uma ampla gama de instituições psicanalíticas que outorgavam para si o mérito de serem herdeiros legítimos da tradição freudiana. Isso levou a equipe editorial a publicar um estudo prévio, justificando os princípios que orientariam as escolhas terminológicas, conceituais e estilísticas (LAPLANCHE, COTET, BOURGUIGNON, 1992), o que não os poupou de críticas ao longo da publicação dos volumes. O trabalho das obras comple- 
tas em francês, embora seja o projeto editorial recente mais sistemático e rigoroso de compilação dos textos freudianos, acabou se mostrando uma tradução bastante específica do ponto de vista da terminologia, já que os editores utilizaram muitos neologismos para delimitar a especificidade dos conceitos psicanalíticos, resultando em um texto muito artificial do ponto de vista estilístico. É, inclusive, uma terminologia bem diferente daquela estabelecida duas décadas antes no vocabulário, e que acabou se tornando referência no jargão psicanalítico internacional, em especial na Europa e na América Latina, incluindo o Brasil.

Fora o trabalho propriamente interpretativo, tradutivo e editorial de Laplanche, suas pesquisas levaram a um caminho de teorização original centrado em problemas fundamentais da psicanálise decorrentes dos referenciais epistemológicos e ontológicos da teoria de Freud. Preocupa-se, sobretudo, em analisar as ambiguidades da teoria e os traços de "recalcamento" de elementos importantes por parte de seu autor. Isso implica afirmar que Laplanche se preocupa mais em "psicanalisar" a teoria psicanalítica do que propriamente fazer uma análise epistemológica clássica de seus conceitos. Isso o coloca como um dos autores, ao lado de Lacan, que propõe um amplo revisionismo dos fundamentos do legado freudiano. Seus questionamentos incidem sobre as origens do aparelho psíquico, articulando a discussão sobre a natureza das pulsões com a teorização sobre o lugar do outro na constituição da subjetividade, o que o levou a propor uma teoria da sedução generalizada como resposta aos impasses metapsicológicos deixados por Freud.

A obra de Laplanche é uma das mais representativas do vigor teórico da psicanálise francesa e se tornou bastante influente na América Latina. É um autor bastante lido no Brasil, em grande parte pelo caráter acadêmico de seu trabalho e pelo intenso intercâmbio entre as instituições universitárias brasileiras e francesas.

\section{QUESTÕES DE MÉTODO E AS Problemáticas}

A caracterização de uma metodologia propriamente psicanalítica de leitura foi um dos méritos de Laplanche. É nos seus seminários de problematização dos conceitos freudianos que vamos encontrar a discussão sobre a questão da compreensão, interpretação e exegese da teoria psicanalítica. Ali encontramos explicitada uma perspectiva dialógica, interpretativa e desconstrutiva, expressa na concepção de fazer o texto trabalhar, por meio da "utilização de conceitos analíticos como chave de uma nova hermenêutica" (LAPLANCHE, 1998a, p. 10). Desse modo, o autor afirma uma posição relativamente original que é a possibilidade de ler os escritos psicanalíticos com o próprio método psicanalítico. Isso significa não uma interpretação das fantasias inconscientes dos autores-psicanalistas, mas a utilização do próprio método psicanalítico como instrumento de leitura da teoria e de seus conceitos. Esse método está baseado em um princípio de análise igualitária, que é o aplainamento ou desmantelamento dos enunciados textuais a partir de uma atenção igualmente flutuante. Com isso, crescem de importância a absurdidade dos detalhes, os esquecimentos e deslocamentos de um texto. A ideia é destituir os "remanejamentos egoicos" (LAPLANCHE, 1988a, p. 30) da doutrina freudiana, desmontando os conceitos da obra.

A ideia fundamental de percorrer a obra em todos os sentidos, sem nada omitir ou privilegiar a priori, possibilitando a emergência de uma problemática que não se resolve linearmente e que, ao contrário, constrói um campo intermediário de exigências teóricas (LAPLANCHE, 1998, p. 10) é um procedimento interpretativo interessante que lança luz sobre a própria concepção do movimento do pensamento freudiano. Cabe assinalar que essa abordagem coloca em questão a própria noção de desenvolvimento teórico. Em vez de um desenvolvimento linear, o que se observa são as contingências da articulação de uma problemática, cuja temporalidade está próxima daquela própria da psicanálise: repetição, 
retorno do reprimido, ressignificação a posteriori, etc. A ideia de uma estrutura do pensamento freudiano, assim, só pode ser entendida no sentido de um equilíbrio dinâmico entre polaridades que nunca se dissolvem.

Trata-se, portanto, de uma perspectiva de leitura histórica, interpretativa e problematizante dos conceitos psicanalíticos, que revela, portanto, um inconsciente no texto, ou seja, uma alteridade radical no próprio nível dos enunciados discursivos que opera, dinamizando um movimento próprio, o qual, por sua vez, implica uma concepção de sentido ou direcionamento último no movimento do pensamento de um autor apenas como uma forma de ideal regulador. Trata-se de uma temporalidade espiral e, ao mesmo tempo, polarizada em torno de oposições. Essas tensões criam linhas de força que possibilitam a concatenação de um desenvolvimento teórico o qual, contudo, não pode ter a pretensão de verdade absoluta, uma vez que essa é histórica e contextualizada.

É essa orientação metodológica que irá orientar todo o trabalho de investigação de Laplanche, sendo fundamento de sua própria atividade de teorização. Como se pode notar, é um procedimento metodológico que tem amplas implicações éticas, pois parte da aplicação da escuta propriamente psicanalítica como instrumento do próprio teorizar, abrindo espaço para uma dimensão de alteridade relativamente nova, mais próxima das discussões contemporâneas acerca da hermenêutica: a alteridade intrínseca ao próprio texto; o texto como agente de efeitos de significação. Portanto, é no rastro do inconsciente no texto e na obra de Freud que Laplanche irá erigir toda a sua revisão das origens do aparelho psíquico e da subjetividade do ponto de vista psicanalítico.

\section{ENTRE O FundAMENTO NATURALISTA E O LINGUÍSTICO}

A preocupação com a natureza do inconsciente e com a teoria da sexualidade é um eixo importante do pensamento de Jean Laplanche, o qual se insere em uma problemática bastante cara ao movimento psicana- lítico francês. Tanto como Lacan, Laplanche também toma para si a tarefa de resgatar os fundamentos da psicanálise e corrigir certas tendências naturalistas, positivistas e funcionalistas da teoria freudiana. O intuito aí é descolar a concepção de sujeito da psicanálise de um fundamento epistemológico próprio das ciências naturais, tal como defendido por Freud. A questão recai sobre a própria concepção de sexualidade como paradigma para pensar a subjetividade humana e seu enraizamento em uma teoria pulsional cuja marca biológica e funcional é patente. Assim, é a própria ideia de pulsão como um impulso natural cuja fonte é somática e que se expressa no psiquismo na forma de representantes, possibilitando a articulação entre as dimensões corporal/biológica e mental/simbólica, que é colocada em questão por Laplanche. Seu grande esforço é descolar definitivamente o registro do desejo do registro da necessidade, endossando a proposta de alinhamento da psicanálise com o campo das ciências humanas e da linguagem típica da psicanálise francesa. Portanto, podemos dizer que uma das características do trabalho de Laplanche é uma crítica ao chamado desvio biologizante do pensamento freudiano.

Contudo, a crítica ao desvio biologizante não chega ao endosso de uma concepção estruturalista pura do sujeito do inconsciente, tal como insistia Lacan na segunda fase de seu pensamento. A preocupação em sair do fundamento biológico e naturalista freudiano sem cair em um fundamento exclusivamente linguístico marcou as primeiras produções psicanalíticas de Laplanche e, também, seu progressivo distanciamento em relação ao antigo mestre.

Já no famoso colóquio de Bonneval sobre o inconsciente, em 1960, Laplanche defende a inversão da proposta lacaniana de referir as leis do processo primário às leis fundamentais da linguística, por meio da submissão dos mecanismos de deslocamento e condensação às figuras da metáfora e da metonímia. Para tanto, parte da referência freudiana da linguagem ao sistema das representações de 
palavra e, portanto, ao pré-consciente e ao processo secundário. Além disso, retoma a hipótese da constituição do inconsciente por meio do recalcamento originário para sustentar níveis de simbolização pré-linguísticos. Define, a partir daí, um encadeamento progressivo de modalidades simbólicas na constituição do aparelho psíquico, da qual apenas o nível mais elevado é de caráter propriamente linguístico: "quanto ao estatuto ontológico do inconsciente assim constituído, será necessário lembrar que, se é um estatuto de linguagem, essa linguagem não pode, em absoluto, ser assimilada à nossa linguagem "verbal"?" (LAPLANCHE e LECLAIRE, 1992, p. 255).

Esse percurso leva os autores a proporem a definição de três formas de simbolização que, por sua vez, remeteriam a três níveis de organização dos conteúdos inconscientes: a imago, a fantasia inconsciente e o complexo. Nessa perspectiva, essas operações simbólicas pré-linguísticas serão condição da emergência da linguagem propriamente dita, o que implica que é o inconsciente a condição da linguagem e não a linguagem condição do inconsciente, como afirmava a tese estruturalista lacaniana. Nas palavras dos autores, tem-se a "perspectiva de um inconsciente estruturado como uma certa linguagem primária e correlato necessário da linguagem propriamente dita" (LAPLANCHE e LECLAIRE, 1992, p. 256).

No momento da chamada excomunhão lacaniana, em 1964, Laplanche escreve com Pontalis um artigo na esteira da conclusão da parceria de ambos no Vocabulário da Psicanálise. Publicado originalmente na famosa revista Tempos Modernos e reeditado 20 anos depois, esse texto é bastante ilustrativo das questões que irão orientar o direcionamento das investigações posteriores de Laplanche. Trata-se de nada mais do que um estudo sobre um conceito fundamental para a metapsicologia: a fantasia. A fantasia é o estofo do aparelho psíquico e da concepção de inconsciente. Discutir a gênese e os desdobramentos do conceito de fantasia em Freud é abordar a própria concepção de representação psíquica e de significação em psicanálise. Nesse texto, o autor claramente procura se distanciar de duas concepções clássicas de fantasia na psicanálise pós-freudiana: a lacaniana, calcada no universalismo da estrutura linguística, e a kleiniana, calcada no individualismo do mundo interno, buscando justamente uma posição intermediária que possa servir de articulação estruturante entre a dimensão interna e a externa da experiência subjetiva. Para tanto, irá resgatar a força da concepção de posterioridade do trauma na teoria da sedução, de Freud, como articulador epistemológico necessário para pensar a subjetividade em psicanálise, o que implicaria, por sua vez, na afirmação de uma sexualidade que se originaria do outro:

Ora, com a teoria da sedução, pode-
-se dizer que todo o traumatismo
provém simultaneamente do ex-
terior e do interior. Do exterior,
porquanto é do outro que a sexua-
lidade chega ao sujeito, do interior,
pois que jorra desse exterior inte-
riorizado, dessa 'reminiscência' de
que, segundo uma bela fórmula, so-
frem os histéricos e na qual já reco-
nhecemos a fantasia (LAPLANCHE e
PONTALIS, 1985, p. 31)

O abandono por Freud da teoria da sedução, por sua vez, levaria a um desequilíbrio e a um apagamento da concepção de fantasia como estrutura pré-subjetiva que mediaria e faria a conjunção entre os dois tempos da "cena" e a uma valorização do polo exclusivamente internalista de uma realidade psíquica. Isso levou os autores a criticarem a saída freudiana que foi afirmar uma fantasia originária de cunho filogenético como recurso para garantir a universalidade do complexo de Édipo.

Assim, embora reconheçam a necessidade de pensar uma fantasia originária para explicar a origem das fantasias e, por conseguinte, de toda a estrutura da subjetividade inconsciente, os autores preferem resgatar o sentido e a estrutura mítica da fantasia, como uma forma de narrativa retroativa sobre os enigmas da história do sujeito. Isso quer dizer 
que a fantasia originária teria uma lógica mítica na medida em que teria um papel estruturante nas origens da subjetividade. Daí propriamente a ideia de que as origens das fantasias próprias de uma pessoa em particular seriam derivações de uma fantasia das origens universal. Evidentemente, é na esteira do mito das origens freudiano e de sua interpretação por Lacan que os autores se colocam, pois também invertem a proposição original para afirmar que é o lugar simbólico do pai morto que cria a possibilidade da encarnação de um pai real. Contudo, se distanciam de Lacan ao criticarem a assimilação da fantasia originária a uma interpretação estruturalista pura em que esta figuraria como uma ordem simbólica universal e impessoal que determinaria a subjetividade. Para tanto, afirmam que enquanto fantasia, ou seja, enredo narrativo imaginário, as fantasias originárias não poderiam ser assimiladas a uma estrutura transcendente:

Não nos apressemos, entretanto, em substituir a 'explicação filogenética' por uma interpretação de tipo estruturalista. Aquém da história do sujeito mas, não obstante, na história, discurso e cadeia simbólica, embora impregnada de imaginário, estrutura, embora arrumada a partir de elementos contingentes, a fantasia originária é, em primeiro lugar, fantasia e como tal marcada por certos traços que a tornam dificilmente assimilável a um puro esquema transcendente, mesmo que venha a fornecer à experiência suas condições de possibilidade (LAPLANCHE e PONTALIS, 1985, p. 55-56)

Portanto, longe de tentarem simplificar a definição de fantasia, os autores ressaltam justamente a sua polissemia e complexidade - articulador entre interno e externo, individual e coletivo, histórico e estrutural - o que justificaria o trinômio do título do artigo: fantasia originária, fantasias das origens, origens da fantasia. A questão passa a ser como então poderíamos compreender a complexidade inerente ao conceito psicanalítico de fantasia. A proposta dos autores é resgatar propriamente a conotação de "cena" nas fantasias em regime de processo primário, em que estas aparecem não tanto como objetos de desejo, mas como uma construção imaginária em que o sujeito não tem lugar, ou melhor, está disperso por todos os lugares. Essa é propriamente a definição do potencial estruturante da fantasia, na medida em que figura como um roteiro de múltiplas entradas:

'Um pai seduz uma filha', tal seria, por exemplo, a formulação resumida da fantasia de sedução. A marca do processo primário não é, nesse caso, a ausência de organização, como às vezes tem sido afirmado, mas esse caráter particular da estrutura: ela constitui um roteiro de múltiplas entradas, no qual nada diz que o sujeito encontrará de imediato o seu lugar no termo filha; é possível vê-lo fixar-se igualmente em pai ou até mesmo em seduz' (LAPLANCHE e PONTALIS, 1985, p. 72)

Fica claro, assim, o intuito de Laplanche em consolidar sua distinção em relação ao percurso de Lacan no que tange à concepção de sujeito em psicanálise. Sua intenção é criticar o desvio biologizante em Freud e sua tendência a afirmar uma constituição autóctone do sujeito. Seu caminho será ressaltar o papel da intersubjetividade na constituição do circuito pulsional e da dimensão de desejo própria do humano. Para tanto, irá seguir a trilha das origens da sexualidade até o exame do tempo hipoteticamente autônomo na gênese do sujeito: o autoerotismo como um estágio natural e anobjetal da libido, que se confundiria com o narcisismo primário no final da obra freudiana.

Esse caminho levará a proposta de isolar a dimensão simbólica, intersubjetiva e indeterminada nos impulsos humanos de sua dimensão propriamente biológica, autóctone e determinada. Enfim, trata-se da famosa 
distinção, cara à psicanálise francesa, entre a ordem do desejo, propriamente pulsional, e a ordem da necessidade, propriamente instintiva. Esse ponto já havia sido estabelecido na terminologia do Vocabulário da Psicanálise (LAPLANCHE e PONTALIS, 1998), mas será aprofundado em uma ampla revisão da teoria pulsional freudiana cujo intuito declarado será integrar as duas teorias pulsionais. Nessa proposta, apresenta uma distinção fundamental entre as funções de autoconservação - antigas pulsões do ego - e as pulsões sexuais, propondo que somente no campo dessas últimas é que se diferenciariam propriamente as pulsões de vida e de morte (LAPLANCHE, $1988 c$, p. 17). Somente a esse segundo grupo caberiam as características próprias da pulsão (fonte, objeto, pressão, meta) que teria, portanto uma origem distinta das funções de autoconservação do organismo, uma vez que seria constituída pela instalação do recalque originário, segundo a teoria da sedução generalizada que propõe.

Tem-se, portanto, que, para Laplanche, a teoria das pulsões teria uma dupla gradação: (1) a distinção entre funções de autoconservação e de pulsões sexuais e, dentro desta segunda categoria, (2) as pulsões de vida e de morte. Embora essa sistematização pareça anular as contradições inerentes à teoria pulsional, a questão não é tão simples. Isso porque as relações entre as funções de autoconservação do organismo e a pulsão sexual são bastante complexas, envolvendo justamente a questão da passagem da função biológica para a sexualidade tal como a investigação psicanalítica pôde concebê-la: uma satisfação de desejo independente de seu objeto e sua função biológica. Não se trata, portanto, de relegar o biológico a um campo distinto do pulsional, mas compreender como o próprio pulsional se infiltra no biológico, destituindo-o de sua posição original. É preciso lembrar que a grande originalidade freudiana é operar a sexualização das funções de autoconservação do indivíduo.

A maior prova disso é a introdução do conceito de narcisismo. Ao afirmar que o ego é sujeito ao investimento da pulsão sexual e que essa etapa é fundamental na constituição dele, o que se tem é o reconhecimento da imbricação profunda entre as funções de autoconservação e a sexualidade. A complexidade dessa relação em Laplanche é atestada pela afirmação de uma relação vicariante entre esses polos da atividade humana, que se sustenta no resgate da hipótese do apoio das pulsões sexuais nas funções de autoconservação para pensar a progressão do desenvolvimento da libido, bem como na metáfora da recuperação dos alicerces para pensar a ação da retroação na constituição da subjetividade:

Recuperar os alicerces é, após escoramento, escavar as fundações para recimentá-las de maneira mais sólida (...) sem ter mudado nada nas estruturas. Evidentemente, forneço essa imagem para figurar a 'vicariança' da auto-conservação pela sexualidade no ser humano (LAPLANCHE, 1992a, p. 65).

Esse percurso teórico de Laplanche mostra a sua concepção própria de sujeito da psicanálise, alicerçada em uma definição própria dos conceitos metapsicológicos fundamentais de inconsciente, fantasia, sexualidade e pulsão. Nessa perspectiva, o sujeito do inconsciente deve ser entendido como uma dimensão constituinte e constitutiva da subjetividade humana, produto de sua condição "linguageira" ou semiótica:

A outra característica, que não é totalmente independente da primeira, é que o objeto da psicanálise não é o objeto humano em geral; não se trata do homem que podemos delimitar através de várias ciências - a psicologia, a sociologia, a história, a antropologia -, mas do objeto humano, na medida em que formula, que dá forma essencialmente na linguagem do tratamento, porém, de maneira mais profunda, este é 
um movimento de sua vida inteira. Uma epistemologia e uma teoria da psicanálise devem levar em conta, na própria base, o fato de que o sujeito humano é um ser teorizante, e teorizante de si mesmo, quero dizer que ele teoriza a si mesmo, que ele se autoteoriza, ou então, se esse termo de teoria mete muito medo, que ele se auto-simboliza. A simbolização que lhe surge no tratamento, interpretação ou auto-interpretação, movimento da interpretação entre o analista e o analisado, essa simbolização é ressimbolização com base em primeiras simbolizações, dessas simbolizações originárias em cujo rastro nos colocaremos necessariamente nesta procura dos fundamentos. (LAPLANCHE, 1992a, p. 10-11)

A busca das origens dessa concepção de sujeito propriamente psicanalítica, por sua vez, seguirá a trilha aberta pela teoria da sedução na discussão sobre a incidência do outro na origem da subjetividade.

\section{SEDUÇÃo GENERALIZADA E INTERSUBJETIVIDADE TRAUMÁTICA}

Como vimos, já no estudo sobre as fantasias originárias, Laplanche afirmou a necessidade de resgatar a teoria da sedução em Freud como elemento importante para a constituição da fantasia. A sequência de seus estudos irá cada vez mais aprofundar o estudo das origens da sexualidade, levando-o a pensar e tematizar com profundidade a problemática do originário na psicanálise. Trata-se de um caminho que parte da discussão do autoerotismo como estágio anobjetal para pensar os efeitos da linguagem sobre o organismo humano na forma de uma sedução generalizada que seria constitutiva do núcleo do inconsciente, por meio do recalque originário.

Isso implica que a problemática do fundamento biológico do sujeito da psicanálise remete, em Laplanche, à discussão sobre o originário, uma vez que retirar a fonte da pul- são de uma concepção biológica e naturalista implica a reconsideração do problema das origens do inconsciente. A saída laplanchiana - assim como a de Lacan - é postular um fundamento estritamente semiótico para as pulsões e para o inconsciente, de tal forma que o inconsciente seja fruto da operação constitutiva da defesa primária.

Os primórdios da teoria da sedução generalizada foram desenvolvidos por Laplanche desde a década de 1960, mas sua plena sistematização e consideração como a síntese de uma contribuição específica ao legado freudiano remetem somente ao final da década de 1970. Ela propõe uma ampla rearticulação dos fundamentos da teoria psicanalítica, priorizando, como o próprio nome já diz, um resgate do papel da sedução, supostamente abandonado ao longo do desenvolvimento da psicanálise.

Como se sabe, a teoria da sedução "restrita" foi uma hipótese adotada no início das investigações psicanalíticas para explicar a gênese do trauma psíquico em função de uma ressignificação de eventos vividos na infância. Foi abandonada em 1897 por Freud e deu lugar a duas concepções que seriam fundamentais para a concepção da Psicanálise como campo de saber, que foram a noção de realidade psíquica, por meio do conceito de fantasia inconsciente, e a concepção de uma sexualidade infantil. Essa teoria da sedução, embora equivocada em seus aspectos restritos, implicava uma concepção revolucionária de temporalidade, que não foi abandonada por Freud: a ideia de um traumatismo em dois tempos, decorrente da significação a posteriori de um registro mnêmico, ou seja, de uma tradução de registros representacionais que implicaria reposicionamentos tópicos. Esses fatores, que Laplanche chama de "força" na teoria da sedução restrita (1988b, p. 112), serão aquisições fundamentais da racionalidade psicanalítica.

A inovação propriamente laplanchiana não está em resgatar os elementos dessa primeira teoria da sedução ou mesmo a noção de a posteriori, mas indicar os remanejamentos finais da obra freudiana no sentido de um resgate da ideia de sedução precoce e 
rearticulá-los em uma teoria coerente sobre o originário. Embora essas indicações estejam presentes na última década do pensamento freudiano, faltou uma ampla restituição da sedução no conjunto da teoria freudiana. Laplanche se propõe a sanar essa falha por meio de uma generalização que parte de uma crítica das concepções de atividade e passividade por meio da ideia de um "a mais" de significação no confronto da criança com o mundo adulto, tributária, por sua vez, das proposições de Ferenczi de uma "confusão de línguas". Segundo esse autor, haveria um traumatismo inerente ao encontro da linguagem adulta com a infantil, resultando em um erro de interpretação da sedução adulta sobre o corpo infantil (LAPLANCHE, 1988b).

Retomando a teoria do trauma e da ressignificação a posteriori, Laplanche resgata uma hipótese bastante remota e por vezes esquecida de Freud, a saber, a de o trauma ser fruto de falhas na ressignificação de diferentes níveis de simbolização operantes no aparelho psíquico. Essa perspectiva mais propriamente semiótica - já que a simbolização é fruto de níveis de interpretação e tradução de sentido das fantasias - faz que o autor venha a se voltar para a questão dos deslizamentos de sentido entre as modalidades de registro de significação, para pensar a fantasia como uma espécie de "erro" de tradução causando um excesso traumático na passagem de uma modalidade de simbolização para outra. A articulação dessa teoria da linguagem marcada por múltiplos níveis de significação com a hipótese de um traumatismo oriundo da "confusão de línguas" entre adulto e criança será o cerne da teoria da sedução generalizada.

Desse modo, é por meio da apropriação da noção ferencziana de uma confusão de línguas entre criança e adulto e de uma consideração bastante ampla do que seriam as modalidades semiológicas (verbalizações, gestos e expressões, afetos, etc.), que Laplanche propõe a ideia fundamental de um potencial traumático da linguagem adulta em função de um sentido ignorado que é expressão do inconsciente parental. Esse será o sentido de uma sedução generalizada do bebê pelos cuidados da função materna como condição necessária para a constituição do circuito pulsional, o que fará que esse momento de identificação primária seja propriamente o momento originário da subjetividade inconsciente. Assim, a origem da pulsão é simultânea ao recalque originário, e se dá por meio de uma identificação narcísica primária com os significantes do desejo materno.

Contudo, diferentemente da concepção lacaniana de um recalque do significante do desejo materno ao qual o sujeito está identificado, Laplanche ressalta que a identificação narcísica não é exatamente especular, no sentido do desejo infantil ser reflexo alienado do desejo materno. Na concepção laplanchiana, esse momento narcísico é traumático porque além da dinâmica positiva da identificação opera também uma dimensão propriamente traumática que é o excesso de sentido perpetrado pelos significantes maternos. Portanto, os significantes maternos, mais do que convocar ao sentido, também instalam enigmas que demandam simbolização. A dinâmica identificatória com os significantes enigmáticos é o que dará origem ao recalque originário:

Pelo termo sedução originária qualificamos, portanto, esta situação fundamental na qual o adulto propõe à criança significantes não-verbais, tanto quanto verbais, e até comportamentais, impregnados de significações sexuais inconscientes. Do que chamo significantes enigmáticos, não é necessário procurar longe para encontrar exemplos concretos. O próprio seio, órgão aparentemente natural da lactação: podemos negligenciar ainda seu investimento sexual e inconsciente maior pela mulher? (LAPLANCHE, 1988b, p. 119).

A característica distintiva da proposta de Laplanche é que o processo identificatório que está na origem do recalque originário é 
fundamentalmente negativo, uma vez que é o resto não simbolizado desses significantes enigmáticos que irá se instalar como o objeto-fonte da pulsão:

Recentemente traçamos o esquema geral com maior precisão a propósito da pulsão. É a confrontação de um indivíduo cujas montagens somatopsíquicas se situam de maneira predominantemente ao nível da necessidade, com significantes emanando do adulto, ligados à satisfação destas necessidades, mas veiculando com eles a potencialidade, a interrogação puramente potencial de outras mensagens sexuais. O trabalho de domínio e de simbolização deste 'significante enigmático' termina necessariamente em restos 'fueros' inconscientes, que chamamos 'objetos-fontes' da pulsão (LAPLANCHE, 1988b, p. 120)

Assim, é essa sedução precoce, originária e generalizada que fornece o solo constitutivo do próprio circuito pulsional. O originário é entendido como fruto de uma confrontação do organismo biológico dotado de montagens somatopsíquicas com significantes emanados do adulto, ligados à satisfação das necessidades biológicas, mas veiculando uma interrogação puramente potencial de mensagens de cunho sexual. Isto quer dizer que é a significação proveniente do outro humano como uma intencionalidade suposta, porém incompreendida, que invoca e constitui a sexualidade. Esses primeiros registros, portanto, indicariam uma forma de registro pré-simbólica, que demandaria tradução em significações mais elaboradas, criando uma exigência constante de simbolização.

Uma apresentação um pouco mais extensa e didática da teoria da sedução generalizada é feita no livro Novos Fundamentos para a Psicanálise (LAPLANCHE, 1992a, p. 111-157) que, ademais, sintetiza muitas das posições desse autor sobre o legado freudiano. Ali, ele irá partir também dos aspectos tópico, temporal e tradutivo da sedução restrita e da teoria do trauma ferencziana para desenvolver sua hipótese de uma sedução originária produzida por significantes enigmáticos. Porém, dessa vez, dá especial atenção para os significantes referentes às fantasias das cenas originárias (nascimento, coito parental, castração, diferença de gêneros, etc.) como os elementos primordiais de incidência do potencial traumático. Com isso, cada vez mais o autor vai se aproximando de uma concepção fundacional sobre a estrutura do aparelho psíquico em que o originário é dissociado da mitologia científica em que Freud o enraizara, a ponto de afirmar que "o originário é um aprofundamento da noção de real (o real humano, evidentemente) em direção às situações inelutáveis que o fundam; o originário é uma categoria da efetividade (LAPLANCHE, 1992b, p. 137).

Desse modo, a sedução originária opera por meio de um fornecimento de significantes enigmáticos que irão encontrar apoio nas funções biológicas de autoconservação. É a intencionalidade semiótica que irá sobrepujar o funcionamento no nível da mera necessidade, implementando uma nova modalidade de regulação. Esse momento, em que o significante enigmático instala-se no corpo e configura propriamente uma zona erógena circunscrevendo limites corporais que serão referências importantes do que virá a ser o ego-instância, é denominado de implantação. O significante enigmático, portanto, é inicialmente externo ao ego, sendo então progressivamente internalizado e inscrito. A estimulação incessante desse resquício traumático engendra mecanismos defensivos que irão progressivamente estabelecendo ressignificações sobre essa marca originária. Essas defesas primárias, que constituem processos de simbolização e são mediadas por identificações com o objeto, irão constituir propriamente o recalcamento originário.

Podemos então afirmar que para Laplanche o ser humano é entendido como um ser semiótico, de caráter autotradutivo 
e autoteorizante, que se origina da operação fundamental em que os significantes enigmáticos se implantam como restos e inscrições mnêmicas rudimentares que atuarão como incitadores do processo de simbolização e engendradores da pulsão. Dessa forma, os significantes enigmáticos são compreendidos como os verdadeiros "objetos-fontes" da pulsão, instalados pelo traumatismo da sexualidade proveniente do outro.

A constituição de todo esse circuito pulsional, por sua vez, seria dada pelo recalcamento originário, que envolveria um processo de substituição significante que o autor denomina de metábole. Esse neologismo assemelha-se às figuras de linguagem da metáfora e da metonímia utilizadas por Lacan em sua própria concepção do recalque originário como advento da metáfora paterna, mas procura ressaltar a ação metabolizante das operações semióticas constituintes do aparelho psíquico e do circuito pulsional:

Propusemos um esquema para esse processo, o da substituição significante ou metábole, com suas diversas modalidades. Relembro aqui o esquema, parcialmente derivado de Lacan, mas numa direção totalmente diferente que, aliás, Lacan criticou especificamente. Trata-se do fato de que um primeiro par significante-significado é submetido à ação de um segundo par que, desta vez, é um par de dois significantes (...) Quando a ligação de S2 com S1 é (no essencial) uma ligação de analogia, essa metábole é chamada de metáfora; quando a ligação entre S2 e S1 é de pura contiguidade, essa metábole é chamada de metonímia. A metábole é, portanto, o gênero comum à metáfora e à metonímia. (...) (LAPLANCHE, 1992a, p. 139-140)

A consolidação dessa operação originária, contudo, dependeria de um segundo momento, aquele do recalque secundário que, em termos laplanchianos, seria propriamente o de introdução do recalque e da identificação paterna por meio da resolução do complexo de Édipo. Isso quer dizer que os mecanismos de interpretação de sentido operam em diversos níveis de simbolização, o que implica que a significação a posteriori não opera apenas no recalcamento originário, estando presente, também, no complexo de Édipo e na dinâmica de identificações, angústias e defesas que levará à formação do superego. Assim, quando a dinâmica triangular se organiza e se configuram o recalcamento propriamente dito e a dinâmica edípica, está em jogo também um movimento de ressignificação, que vem confirmar, reforçar e consolidar as próprias fantasias originárias, ou nas palavras de Laplanche: "o recalcamento originário necessita de uma chancela para ser mantido, necessita do recalcamento secundário" (1992a, p. 145). Decorrerá daí um maior escalonamento de níveis do aparelho psíquico, comportando agora a instância superegoica. De qualquer forma, é importante entender que, na lógica laplanchiana, não se trata propriamente de uma nova inscrição independente da anterior, mas de uma mudança no estatuto dessas significações, por meio de modificações em suas relações de simbolização.

O que é particularmente interessante dessa proposta é a afirmação peremptória do papel do outro na constituição da subjetividade. Além disso, sua concepção de originário implica uma compreensão semiótica e não biológica das origens do inconsciente e da pulsão. Como podemos ver, trata-se de um autor que honra a tradição francesa de reposicionamento epistemológico dos fundamentos da psicanálise, colocando em evidência o papel da alteridade e da linguagem na definição do objeto próprio da psicanálise: o inconsciente.

Pode se notar que o percurso laplanchiano se aproxima das concepções lacanianas. Contudo, toda a proposta laplanchiana surge de sua crítica à primazia da linguagem concedida por Lacan na compreensão do inconsciente e envereda por uma noção mais ampla do que viria a ser o "significante", uma vez que esse 
não se restringiria apenas a signos linguísticos, mas a uma gama mais ampla de articulações semióticas, incluindo aspectos verbais e imagéticos, além do próprio hiato inerente aos processos de interpretação que implica, portanto, em uma negatividade intrínseca aos processos de linguagem. Pode-se afirmar, portanto, que a diferença fundamental entre as perspectivas dos dois autores é o caráter do significante, que era entendido de forma extremamente restrita na concepção estrutural lacaniana e passa a ser bem mais ampla na concepção hermenêutica laplanchiana. Além disso, Laplanche vem ressaltar também a importância fundamental dos afetos na teoria psicanalítica e sua resistência a conformação da subjetividade a um registro puramente semiótico. Daí, inclusive, a importância de seus estudos sobre a angústia para pensar a teoria psicanalítica (LAPLANCHE, 1998).

Nisso Laplanche fez coro com outros críticos da fase mais estruturalista de Lacan. É verdade, por outro lado, que precisamos fazer justiça e lembrar que os próprios desdobramentos da teoria lacaniana e do lacanismo seguiram no sentido de ultrapassar essas limitações de um estruturalismo linguístico estrito na abordagem do sujeito do inconsciente.

Outro aspecto, contudo, precisa ser ressaltado no que tange às contribuições específicas de Laplanche. Trata-se do caráter mais propriamente traumático que a experiência intersubjetiva tem na constituição da subjetividade. Aqui Laplanche também é representativo da tradição francesa em psicanálise, que insiste na concepção de uma violência simbólica como condição de instauração da subjetividade (COSTA, 1988). Representa também claramente uma posição teórica em psicanálise que ressalta a relevância e a prevalência de uma intersubjetividade traumática (COELHO JUNIOR e FIGUEIREDO, 2003, 2004) na consideração da subjetividade humana.

Tem-se, portanto, que por meio de uma teoria da sedução generalizada Laplanche chega à proposição de uma intersubjetividade traumática na constituição originária da subjetividade. Nessa perspectiva, o circuito pulsional se origina da instalação do objeto-fonte da pulsão que é fruto da demanda de interpretação e da inscrição e em negativo da linguagem do outro sobre o organismo humano. É uma espécie de "resto não assimilado" por meio do qual a pulsão brota, ou seja, trata-se de uma negatividade e de uma irrepresentabilidade fundantes, o que vem corroborar a ideia de que a pulsão de morte é a condição originária da vida pulsional. Assim, podemos notar que, tal como a fantasia, a pulsão tem um originário, pois é simultaneamente efeito e causa da alteridade radical no seio da subjetividade, o que reitera a sua posição como conceito fundamental da psicanálise.

\section{CONCLUSÃo}

Neste artigo, partimos do histórico e da contextualização da obra de Jean Laplanche para indicar sua pertinência e relevância para a psicanálise. Para entender seu alcance, precisamos entender a proposta de revisionismo dos fundamentos da psicanálise tanto no nível da teoria quanto no do método. Partimos então para a apresentação das concepções de sedução, fantasia e recalque originários, chegando não só a uma correção do desvio biologizante na teoria da sexualidade, como também a uma afirmação do papel fundamental do outro na constituição do sujeito do inconsciente e, por conseguinte, para a própria concepção de homem.

Ao fim desse percurso, podemos afirmar que Laplanche é um dos autores da psicanálise contemporânea que insiste no posicionamento ontológico e epistemológico que reconhece a alteridade como aspecto fundamental da subjetividade. Sua concepção específica de sujeito da psicanálise, por sua vez, endossa a dimensão propriamente traumática da subjetividade em seu nível originário, colocando a violência simbólica como um aspecto constitutivo do inconsciente e do circuito pulsional. Sua concepção de subjetividade ressalta a dimensão propriamente enigmática, histórica e singular dos processos de simbolização, em detrimento de positividade de uma suposição puramente estrutural de sujeito. 
O sentido geral dessas proposições conceituais é a afirmação da alteridade como categoria central para a psicanálise, implicando, necessariamente, um posicionamento ético de acolhimento da diferença, valorização dos conflitos e interpretação dos sentidos como forma de elaboração do desejo. Isso faz desse autor, portanto, uma referência fundamental para a discussão sobre a alteridade e a ética em psicanálise.

\section{REFERÊNCIAS}

EY, Henri. O Inconsciente: VI Colóquio de Bonneval. Vol.1. Rio de Janeiro: Tempo Brasileiro, 1969. COELHO Jr., N. E., FIGUEIREDO, L. C. Patterns of intersubjectivity in the constitution of subjectivity: dimensions of otherness. Culture \& Psychology, v. 9, n. 3, p. 193-208, 2003.

COELHO Jr., N. E., FIGUEIREDO, L. C. Figuras da intersubjetividade na constituição subjetiva: dimensões da alteridade. Interações, v. IX, n. 17, p. 9-28, 2004.

COSTA, J. F. Violência e Psicanálise. 3. ed. Rio de Janeiro: Graal, 2003.

LAPLANCHE, J. Interpretar com Freud. In: LAPLANCHE, J. Teoria da sedução generalizada e outros ensaios. Porto Alegre: Artes Médicas, 1988a, p. 21-32.

LAPLANCHE, J. Da teoria da sedução restrita à teoria da sedução generalizada. In J. LAPLANCHE, Teoria da sedução generalizada e outros ensaios. Porto Alegre: Artes Médicas, 1988b, p. 108-125. LAPLANCHE, J. A pulsão de morte na teoria da pulsão sexual. In: WIDLÖCHER et. al., A pulsão de morte. São Paulo: Escuta, 1988c, p. 11-28.

LAPLANCHE, J. Problemáticas II: castração - simbolizações. São Paulo: Martins Fontes, 1988d. LAPLANCHE, J. Problemáticas III: a sublimação. São Paulo: Martins Fontes, 1989.

LAPLANCHE, J. Novos fundamentos para a psicanálise. São Paulo: Martins Fontes, 1992a.

LAPLANCHE, J. Problemáticas IV: o inconsciente e o id. São Paulo: Martins Fontes, 1992b.

LAPLANCHE, J. Problemáticas V: a tina: a transcendência da transferência. São Paulo: Martins Fontes, 1993.

LAPLANCHE, J. Problemáticas I: a angústia. 3. ed. São Paulo: Martins Fontes, 1998.

LAPLANCHE, J.; COTET, P.; BOURGUIGNON, A. Traduzir Freud. São Paulo: Martins Fontes, 1992. LAPLANCHE, J.; LECLAIRE, S. O inconsciente: um estudo psicanalítico. In: LAPLANCHE, J. Problemáticas IV: o inconsciente e o id. São Paulo: Martins Fontes, 1992, p. 215-266.

LAPLANCHE, J.; PONTALIS, J.-B. Fantasia originária, fantasia das origens, origens da fantasia. Rio de Janeiro: Zahar, 1985.

LAPLANCHE, J.; PONTALIS, J.-B. Vocabulário da Psicanálise. 3 ed. São Paulo: Martins Fontes, 1998. ROUDINESCO, E.; PLON, M. Dicionário de Psicanálise. Rio de Janeiro: Zahar, 1998.

DADOS DO AUTOR:

Érico BRUNO VIANA CAMPOS (UNESP)

Psicólogo, mestre e doutor em psicologia pelo IP-USP

Professor assistente doutor do departamento de psicologia da Faculdade de Ciências da UNESP em Bauru

Recebido: $18 / 10 / 2011$ Aprovado: 25/09/2012 